\title{
Correction to: The model structure of the copper-dependent ammonia Monooxygenase
}

\author{
Francesco Musiani ${ }^{1}\left(\mathbb{D} \cdot\right.$ Valquiria Broll $^{1}\left[\right.$ [ $\cdot$ Elisa Evangelisti ${ }^{1} \cdot$ Stefano Ciurli ${ }^{1}([)$
}

Published online: 27 February 2021

(c) Society for Biological Inorganic Chemistry (SBIC) 2021

\section{Correction to: JBIC Journal of Biological Inorganic Chemistry (2020) 25:995-1007 https://doi.org/10.1007/s00775-020-01820-0}

In the original article published, the authors missed to acknowledging an article published by Liew et al. (Mutagenesis of the hydrocarbon monooxygenase indicates a metal centre in subunit- $\mathrm{C}$, and not subunit-B, is essential for copper-containing membrane monooxygenase activity, Microbiology 2014, 160, 1267-1277).

"Thus far, however, the crystal structures have not fully established the location and composition of the pMMO active site [48], but all evidence points to either the $\mathrm{CuB}$ or the $\mathrm{CuC}$ site for this role. It is the opinion of the authors of the present study that the latter, with its labile water-bound position, should more logically constitute the enzyme active metal site. This conclusion is strongly supported by site-directed mutagenesis studies on the copper-dependent hydrocarbon monooxygenase (HMO) from Mycobacterium NBB4 which provided the first evidence that the $\mathrm{C}$ site was essential for activity, whereas mutations in the $\mathrm{B}$ site impaired, but did not eliminate, activity (E. F. Liew, D. Tong, N. V. Coleman, A. J. Holmes, Microbiology 2014, 160, 1267-1277)".

Publisher's Note Springer Nature remains neutral with regard to jurisdictional claims in published maps and institutional affiliations.

The original article can be found online at https://doi.org/10.1007/ s00775-020-01820-0.

Francesco Musiani

francesco.musiani@unibo.it

Stefano Ciurli

stefano.ciurli@unibo.it

1 Laboratory of Bioinorganic Chemistry, Department of Pharmacy and Biotechnology, University of Bologna, Viale G. Fanin 40, 40127 Bologna, Italy 